\title{
Open Science, Cardiology and 20 years of SciELO (Scientific Electronic Library Online)
}

\author{
Claudio Tinoco Mesquita, ${ }^{1,2,3}{ }^{\circledR}$ Danielle Borim, ${ }^{4}$ Carlos Eduardo Rochitte ${ }^{5,6,7}{ }^{\oplus}$ \\ Universidade Federal Fluminense, ${ }^{1}$ Niterói, RJ - Brazil \\ Hospital Pró-Cardíaco, ${ }^{2}$ Rio de Janeiro, RJ - Brazil \\ International Journal of Cardiovascular Sciences, ${ }^{3}$ Rio de Janeiro, $R J$ - Brazil \\ Sociedade Brasileira de Cardiologia, ${ }^{4}$ Rio de Janeiro, $R J$ - Brazil \\ Instituto do Coração (InCor) - Faculdade de Medicina da Universidade de São Paulo, ${ }^{5}$ São Paulo, SP - Brazil \\ Hospital do Coração (HCOR), ${ }^{6}$ São Paulo, SP-Brazil \\ Arquivos Brasileiros de Cardiologia, ${ }^{7}$ Rio de Janeiro, RJ - Brazil
}

Science knows no country, because knowledge belongs to humanity, and is the torch which illuminates the world.

Louis Pasteur

The SciELO 20 Years Conference, held from September 24 to 28, 2018, in São Paulo, was remarkable in many ways, as it represented the recognition of one of the most important scientific initiatives in Latin America and a focal point for the latest innovations in scientific thinking these days. The focus of the meeting was "Open Science," which is the practice of science that allows collaboration and contribution among researchers, where research data, laboratory observations and other research processes are available free of charge, under terms that allow the reuse, redistribution and reproduction of research and its underlying data and methods. In the past, Open Science consisted in efforts to offer open access to articles in view of the increasing journal subscription costs charged by the publishers, but the movement quickly condensed several democratizing initiatives of knowledge. ${ }^{1}$ This innovative and disruptive way of understanding the very meaning of science has been recently analyzed by Vicente-Saez and Martinez-Fuentes, who concluded that the best definition for Open Science

\section{Keywords}

Access to Information; Biomedical Research; Open Access Publishing/standards; Open Access Publishing/ history; Open Access Publishing/trends; Information Dissemination/methods; Costs and Costs Analysis; Publishing/economics. is transparent and accessible knowledge that is shared and developed through collaborative networks (Figure 1). ${ }^{2}$ Current trends in Open Science were addressed at the SciELO 20 Years Conference and are in line with the path mapped out for the journals of the Brazilian Society of Cardiology, such as: open codes, open data, open access to articles, alternative systems for assessing the impact of publications (social impact factor), open data sheets, open laboratory notes, science blogs, collaborative references, citizen science, online data repositories, open peer reviews and access to the manuscripts before they are peer-reviewed (preprints). ${ }^{1}$

The multiple advantages of Open Science include access of information to a bigger number of people, the possibility of building collaborative knowledge to make scientific growth faster, and greater scientific visibility of data, as well as faster access to scientific information. With access to research data, these can be checked by anyone who accesses the data repository. Opening of data reduces the possibilities of scientific misconduct, such as plagiarism, fabrication and falsification of data. ${ }^{3}$ Another advantage of open data is the possibility of combining data from different research studies, allowing the generation of new information and answers to questions that would be difficult to be answered individually.

Open science is not only about free-access scientific articles. It involves a much greater movement of encouraging publication in free-access journals and standardizing information to facilitate access by data analysis tools. Another very important initiative is the one that makes science more popular and widespread, by changing the behavior of scientific community, so that the scientists can be more open towards each other

Mailing Address: Claudio Tinoco Mesquita

Pós-Graduação em Ciências Cardiovasculares, Avenida Marques do Paraná, 303. Postal Code: 24033-900, Centro, Niterói, Rio de Janeiro, RJ - Brazil. E-mail: claudiotinocomesquita@id.uff.br 
and with the public and the media. ${ }^{4}$ Making society more aware of science is fundamental in order to avoid the dissemination of fake news, which has caused significantly adverse impacts, such as the decline in vaccination figures. ${ }^{5}$

In short, the movement for open science is irreversible, with data showing that in 2016, about one in every five published articles was immediately available after publication, either by access in open journals (15\%) or because the authors had paid for publication in journals that require an amount to be paid to make the manuscript open to the readers on a free-of-charge basis (the so-called gold open access model). ${ }^{6}$ The European Union's initiative to require that articles resulting from research funded by public research funding agencies be published only in open-access journals from January 2020 is one of the most hard-hitting ways to encourage the dissemination of open science (S Plan). ${ }^{6}$ Many people question whether the model of scientific publications will be sustainable in the future, and whether closed-access journals requiring paid subscriptions will be thrive in this fast-changing scenario. The International Journal of Cardiovascular Sciences and Arquivos Brasileiros de Cardiologia have been closely watching this global initiative, whose main characteristics include the promotion of cardiovascular knowledge among its readers in a free and open way, with no publication costs and with the incorporation of new scientific progress approaches, such as acceptance of preprints and encouragement to include databases in online repositories.

\section{References}

1. Albagli S. Ciência aberta como instrumento de democratização do saber [Editorial]. Trab educ saúde. [Internet] 2017;15(3):659-60. [Cited in 2019 Feb 14].Available from: http:/ / www.scielo.br/scielo.php?script=sci_ arttext\&pid=S1981-77462017000300659\&lng=pt\&tlng=pt

2. Vicente-Saez R, Martinez-Fuentes C. Open Science now: A systematic literature review for an integrated definition. J Bus Res. 2018;88(C):428-36.

3. Mesquita CT. Integrity in Scientific Research. Int J Cardiovasc Sci. [Internet] 2017;30(1):1-3. [Cited in 2019 Feb 10]. Available from: http:/ / www.nap.edu/catalog/10430

4. Albagli S, Clinio A, Raychtock S. Ciência aberta: correntes interpretativas e tipos de ação $\square$ Open Science: interpretive trends and types of action. Liinc em Rev. 2014;10(2):434-50.

5. Bozzola E, Spina G, Russo R, Bozzola M, Corsello G, Villani A. Mandatory vaccinations in European countries, undocumented information, false news and the impact on vaccination uptake: The position of the Italian pediatric society. Ital J Pediatr. 2018;44(1):1-4.

6. Haug CJ. No Free Lunch — What Price Plan S for Scientific Publishing? N Engl J Med. 2019;380(12):1181-5. 